\title{
Editorial Report 2014
}

\author{
Jan van Ours
}

Published online: 29 January 2015

(C) Springer Science+Business Media New York 2015

The 4 issues of De Economist published in 2014 contain 20 papers of which 14 papers were published in regular issues and 6 papers were published in a special issue with guest editor Rob Euwals on the labor market for older workers. The impact factor of De Economist increased from 0.26 in 2008 to 0.80 in 2012. The 2013 impact factor was 1.02 .

The table below provides additional information. In 2014 there were 47 regular submissions, about the same as in 2012. As shown, of these submissions so far 8 were accepted, 35 were rejected, and 4 are still in the editorial process. Of the rejected papers 25 were desk-rejections, i.e. rejected within a week after submission. Excluding the papers which were desk-rejected there were 22 regular submissions. This is a small decline compared to 2013 when excluding the desk-rejections, there were 24 regular submissions. Of the papers excluding desk rejections the acceptance rate in 2013 was 50 percent. In 2014 this was 36 percent, but there are still 4 papers in the editorial process so the 2014 acceptance rate will go up in the course of 2015. The table also shows that the average duration until first decision-revise \& resubmit or rejectionwent down further from 63 days in 2013 to 49 days in 2013.

Finally, the table shows the relationship between year of submission and year of publication. For example, of the 16 papers submitted and accepted for publication in 2014, 10 were published in 2014 while the remaining 6 will be published in 2015 .

Since 2011 the editors allow authors to include in the submission editorial letters and referee reports from failed submissions at other journals. This does not mean that no other referees will be used, but the use of previous information will speed of our editorial process.

\footnotetext{
J. van Ours $(\varangle)$

Tilburg, The Netherlands

e-mail: deeconomist@gmail.com
} 


\begin{tabular}{lrrrr}
\hline Number of papers submitted in & 2014 & 2013 & 2012 & 2011 \\
\hline Accepted & 8 & 12 & 10 & 8 \\
Regular rejection & 10 & 12 & 19 & 18 \\
Desk rejection & 25 & 25 & 15 & 17 \\
Stock December 31, 2014 & 4 & 0 & 0 & 0 \\
Sub-total regular submissions & 47 & 49 & 44 & 43 \\
Special issues + editors contributions & 8 & 10 & 4 & 9 \\
Total & 55 & 59 & 48 & 52 \\
\hline Regular papers excl. desk rejections & 22 & 24 & 29 & 26 \\
Number & 36 & 50 & 34 & 31 \\
Acceptance rates (\%) & 49 & 63 & 81 & 108 \\
Days to first decision & 16 & 22 & 14 & 17 \\
\hline Accepted papers & & & & \\
Published in & 6 & 2 & - & - \\
2015 & 10 & 9 & 1 & - \\
2014 & - & 11 & 8 & 14 \\
2013 & - & - & 5 & 2 \\
2012 & - & & - & \\
2011 & & & & \\
\hline
\end{tabular}

The editors of De Economist would like to thank the following reviewers for their contribution to the editorial process:

\begin{tabular}{lll}
\hline Michele Belloni & Leon Bettendorf & Lans Bovenberg \\
Peter Broer & Harry van Dalen & Thomas Dohmen \\
Nick Draper & Peter van Els & Maria Grydaki \\
Robert Inklaar & Guyonne Kalb & Marike Knoef \\
Pierre Koning & Hans Koster & Gerard Kuper \\
Gerwin van der Laan & Michiel van Leuvensteijn & Geert Mesters \\
Jochen Mierau & Petros Milionis & Franz Palm \\
Steven Poelhekke & Ward Romp & Jan Rouwendal \\
Martin Salm & Peter Schotman & Arthur van Soest \\
Laura Spierdijk & Otto Swank & Domenico Tabasso \\
Vincent Vandenberghe & Marno Verbeek & Harry Verbon \\
Aico van Vuuren & Daniel van Vuuren & Arjen van Witteloostuijn \\
\hline
\end{tabular}

